\title{
Direct Torque Fuzzy Controlled Drive for Multi-phase IPMSM Based on SVM Technique
}

\author{
${\text { Fayçal Mehedi }{ }^{*}, \text { Adil Yahdou}^{1}, \text { Abdelkadir Belhadj Djilali }^{1}, \text { Habib Benbouhenni }}^{2}$ \\ ${ }^{1}$ Electrical Engineering Department, Hassiba Benbouali University, Laboratoire Génie Electrique et Energies Renouvelables \\ (LGEER), Chlef 02000, Algeria \\ ${ }^{2}$ ENP Maurice Audin, Oran 31000, Algeria
}

Corresponding Author Email: f.mehedi@univ-chlef.dz

https://doi.org/10.18280/jesa.530213

Received: 8 December 2019

Accepted: 19 February 2020

\author{
Keywords: \\ direct torque control, stator flux ripple, fuzzy \\ logic controller, multi-phase interior \\ permanent magnet synchronous motor, \\ torque ripple, space vector modulation
}

\begin{abstract}
This work presents an improved Direct Torque Control (DTC) method for a 5-phase interior permanent magnet synchronous motor (5P-IPMSM) based on space vector modulation (SVM) and fuzzy logic (FL). In this proposed DTC control, we replaced the traditional proportional-integral (PI) by the FL controller. The main goal is to improve system performance by minimizing the ripple of the stator flux and the torque ripples. The proposed control technique applied on the 5P-IPMSM is verified by Matlab/Simulink software followed by an analyzed and compared to verify the effectiveness of the proposed method. Many improvements have been made to the stator flux ripples, torque ripples, rise time and the robustness to disturbance.
\end{abstract}

\section{INTRODUCTION}

Multiphase machines (MPMs) have useful properties compared to a traditional three-phase system [1]. Among them, for the same power rating, the phase currents are much smaller in MPMs and characterized by an inherent fault tolerance that can be improved $[2,3]$. As for the application areas, they are many and varied, such as automobiles and the wind energy conversion system $[4,5]$.

Direct torque control (DTC) is the most important method used nowadays. The DTC strategy was first proposed for the induction motor (IM) in 1985 by Takahashi et al. [6]. The basic idea of this technique is a direct command of the stator flux and torque of IM without any pulse width modulation (PWM) strategy and proportional-integral (PI) controllers. However, this method is a simple structure compared to the fieldoriented control (FOC) strategy. In this method, the switching table is used to control the inverter. On the other hand, the DTC method has many advantages, the fast dynamic response, lower parameter dependency, and reliability. But, the principal drawbacks, is the stator flux and torque ripples [7, 8].

A DTC control scheme was proposed to control permanent synchrone motor (PMSM) [9]. A DTC technique was designed to regulate the torque of the doubly fed induction machine (DFIM) [10]. The authors [11] propose a DTC strategy based on the neural controller. In this proposed DTC control, the switching table is replaced by artificial neural networks (ANNs) controller. The DTC control is proposed to command the IM drive using a five-level neutral point clamped (NPC) inverter [12]. This proposed technique minimized the total harmonic distortion (THD) of voltage and torque ripple compared to classical DTC strategy. The DTC method was proposed based on space vector modulation (SVM) to command IM drive by using two PI controllers [13].

DTC control scheme was proposed based on second order sliding mode control (SOSMC) to command the DFIG-based wind power [14]. The switching table of DTC control is replaced by the fuzzy logic controller (FLC) [15]. This proposed strategy is simple scheme and minimize the ripples in torque and stator flux. The authors propose a four-level DTC strategy with the ANN controller by using neural PI controller of speed [16]. The switching table of DTC is replaced by ANN controller and PI controller of speed by using fuzzy controller [17].

The direct flux and torque control of speed sensorless fivephase interior permanent magnet synchronous motor (5PIPMSM) based on adaptive sliding mode control (ASMC) is presented [18]. A new fault tolerant drives for a 5P-IPMSM to achieve the MTPA operation (maximum torque per ampere) under open-circuit faults [19]. On the other hand, the 5PIPMSM is an MPM and reduces the electromagnetic torque compared to the classical PMSM. The DTC strategy of 5PIPMSM based on adaptive input-output feedback linearization (AIOFL) is presented [20]. A SOSMC technique was proposed to control the two 5P-IPMSM drives [21]. FLC technique and sliding mode control (SMC) control are combined to regulate the torque and speed of 5P-IPMSM [22]. The author proposes a comparison between classical DTC and DTC with SVM technique for five-phase induction motor [23].

In this work, we propose a new DTC method based on the FLC technique named DTC-SVM-Fuzzy. The original contribution is the application of the intelligent control in the DTC method by using SVM technique and simulation investigation of this new method. The main advantages of the DTC-SVM-Fuzzy method are the simplicity of implementation and minimizing the ripple of the stator flux and the torque ripples compared to a traditional DTC system and DTC-SVM with PI controller of the 5P-IPMSM.

\section{CONVENTIONAL DTC STRATEGY}

The principle of DTC method is presented in detail in the papers [6-18]. To learn DTC strategy, we review some of the 
equations of 5-phase IPMSM. The electromagnetic torque is written in terms of current and stator flux as [24]:

$$
T_{e}=\frac{5}{2} P\left(\Phi_{\alpha} i_{\beta}-\Phi_{\beta} i_{\alpha}\right)
$$

The switching states of the inverter are determined by flux and torque errors, as shown in Eq. (2):

$$
\left\{\begin{array}{l}
\Delta T_{e}=T_{e}^{*}-T_{e} \\
\Delta \Phi_{s}=\Phi_{s}^{*}-\Phi_{s}
\end{array}\right.
$$

where,

$T_{e}{ }^{*}:$ Reference torque.

$\Phi_{s}{ }^{*}$ : Reference flux.

Using the quantities of Concordia, the amplitude of the stator flux is expressed by:

$$
\Phi_{s}=\sqrt{\Phi_{\alpha}^{2}+\Phi_{\beta}^{2}}
$$

And position of the stator flux:

$$
\theta_{s}=\tan ^{-1} \frac{\Phi_{\beta}}{\Phi_{\alpha}}
$$

The DTC-ST control scheme contains three control loops: the control loop for the electromagnetic torque in which the hysteresis comparator, as well as the control loop for the magnitude of the flux has a hysteresis comparator, while the speed control loop for the motor has a PI regulator. In addition, the classic DTC is a simple control scheme and easy to implement compared to vector control. However, this strategy gives more ripples in stator flux and electromagnetic torque, due to the variable switching frequency.

Listwan and Pieńkowski [23] proposed a new switching table for classical DTC of the five-phase IPMSM drives; this proposed switching table is given in Table 1. On the other hand, the modeling of a 5-phase IPMSM is expressed in a rotary frame d-q-x-y as $[25,26]$ :

The state equation of stator voltage:

\begin{tabular}{|c|c|c|c|c|c|c|}
\hline$d \phi$ & & +1 & & & 0 & \\
\hline$d T$ & +1 & (0 & -1 & +1 & 0 & -1 \\
\hline $\mathbf{S}_{1}$ & 24 & 0 & 17 & 14 & 31 & 7 \\
\hline $\mathbf{S}_{2}$ & 28 & 31 & 25 & 6 & 0 & 3 \\
\hline $\mathbf{S}_{\mathbf{3}}$ & 12 & 0 & 24 & 7 & 31 & 19 \\
\hline
\end{tabular}

$$
\left\{\begin{array}{l}
v_{d s}=R_{s} i_{d s}+\frac{d}{d t} \Phi_{d s}-w_{r} \Phi_{q s} \\
v_{q s}=R_{s} i_{q s}+\frac{d}{d t} \Phi_{q s}+w_{r} \Phi_{d s} \\
v_{x s}=R_{s} i_{x s}+\frac{d}{d t} \Phi_{x s} \\
v_{y s}=R_{s} i_{y s}+\frac{d}{d t} \Phi_{y s} \\
v_{0 s}=R_{s} i_{0 s}+\frac{d}{d t} \Phi_{s 0}
\end{array}\right.
$$

Table 1. Switching table for conventional DTC

\begin{tabular}{ccccccc}
\hline $\mathbf{S}_{\mathbf{4}}$ & 14 & 31 & 28 & 3 & 0 & 17 \\
$\mathbf{S}_{\mathbf{5}}$ & 6 & 0 & 12 & 19 & 31 & 25 \\
$\mathbf{S}_{\mathbf{6}}$ & 7 & 31 & 14 & 17 & 0 & 24 \\
$\mathbf{S}_{7}$ & 3 & 0 & 6 & 25 & 31 & 28 \\
$\mathbf{S}_{\mathbf{8}}$ & 19 & 31 & 7 & 24 & 0 & 12 \\
$\mathbf{S}_{9}$ & 17 & 0 & 3 & 28 & 31 & 14 \\
$\mathbf{S}_{\mathbf{1 0}}$ & 25 & 31 & 19 & 12 & 0 & 6 \\
\hline
\end{tabular}

Flux linkages equation as follows:

$$
\left\{\begin{array}{l}
\Phi_{d s}=L_{d} i_{d s}+\phi_{f} \\
\Phi_{q s}=L_{q} i_{q s} \\
\Phi_{x s}=L_{l s} i_{x s} \\
\Phi_{y s}=L_{l s} i_{y s} \\
\Phi_{s 0}=L_{l s} i_{0 s}
\end{array}\right.
$$

The electromagnetic torque is expressed as follow:

$$
T_{e}=\frac{5}{2} P\left(\left(L_{d}-L_{q}\right) i_{d s} i_{q s}+\phi_{f} i_{q s}\right)
$$

The fundamental equation of dynamics is:

$$
J_{m} \frac{d w_{r}}{d t}=p T_{e}-p T_{r}-f_{m} w_{r}
$$

\section{DTC-SVM WITH PI CONTROLLER}

To improve classic DTC performance of the five-phase IPMSM, we propose using a new DTC control scheme with SVM technique. However, the DTC-SVM method is a simple scheme and reduces stator flux ripple and electromagnetic torque ripple compared to the classic DTC and vector control.

A 5-phase vector provides a total of thirty-two spatial vectors, of which thirty are active vectors and two are zero vectors. The 30 vectors extend over 360 degrees in a twodimensional plane, forming a decagon with ten sectors of 36 degrees each. The 5-phase SVM can be applied using a two or four vector method. The active switching vectors are divided in to three groups; large, medium and small switching vectors. The active switching vectors are divided in to 3 groups: small, large and medium switching vectors. Figure 1 (a) and Figure 1 (b) illustrate the active vectors for $\alpha-\beta$ frame and $x$-y frame, respectively $[27,28]$.

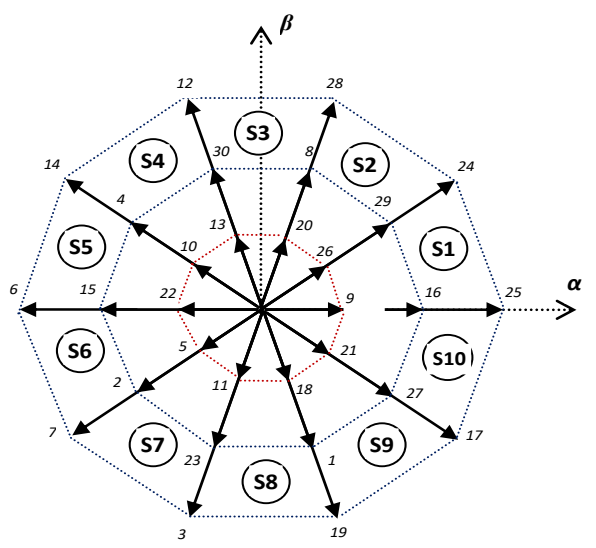

(a) 


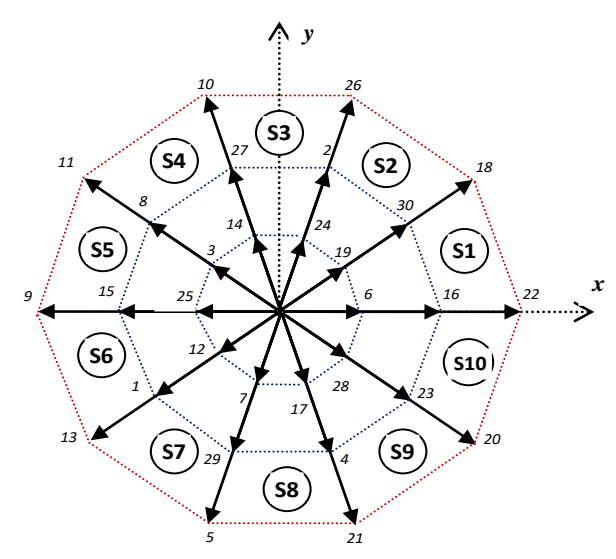

(b)

Figure 1. The voltage space vectors and the switching states of the five-phase inverter in: (a) $\alpha-\beta$ frame, (b) $x-y$ frame

The expression for switching time (ST) using the fourvector method is given as follows:

$$
\begin{gathered}
V_{s}^{*} T_{s}=V_{a l} T_{a l}+V_{b l} T_{b l}+V_{a m} T_{a m}+V_{b m} T_{b m} \\
\left\{\begin{array}{l}
\left|V_{a l}\right|=\left|V_{b l}\right|=\left|V_{l}\right|=\frac{2}{5} V_{d c} 2 \cos \left(\frac{\pi}{5}\right) \\
\left|V_{a m}\right|=\left|V_{b m}\right|=\left|V_{m}\right|=\frac{2}{5} V_{d c} \\
\frac{T_{a l}}{T_{a m}}=\frac{T_{b l}}{T_{b m}}=\frac{\left|V_{l}\right|}{\left|V_{m}\right|}=\tau=1.618
\end{array}\right.
\end{gathered}
$$

We find the equation for the ST by solving equation (9), (10) and (11). These are as follows:

$$
\left\{\begin{array}{l}
T_{a m}=\frac{\left|0.2764 V_{r e f}\right| \sin (k \pi / 5-\theta)}{\left|V_{m}\right| \sin (\pi / 5)} T_{s} \\
T_{a l}=\frac{\left|0.7236 V_{r e f}\right| \sin (k \pi / 5-\theta)}{\left|V_{l}\right| \sin (\pi / 5)} T_{s} \\
T_{b m}=\frac{\left|0.2764 V_{r e f}\right| \sin (\theta-(k-1) \pi / 5)}{\left|V_{m}\right| \sin (\pi / 5)} T_{s} \\
T_{b l}=\frac{\left|0.2764 V_{r e f}\right| \sin (\theta-(k-1) \pi / 5)}{\left|V_{l}\right| \sin (\pi / 5)} T_{s} \\
T_{0}=T_{s}-\left(T_{a m}+T_{a l}+T_{b m}+T_{b l}\right)
\end{array}\right.
$$

where, $T_{s}$ switching period; $T_{a m}, T_{b m}$ the ST of medium voltage vectors; $T_{0}$ the ST of zero voltage vectors; $T_{a l}, T_{b l}$ the ST of long voltage vectors; $\theta$ the angle of position of reference voltage vector; $V_{\text {ref }}$ reference voltage vector; $k$ number of sector.

To optimize the performance of the DTC strategy and the application of a fixed switching frequency, the hysteresis comparator in a DTC traditional is compensated by PI stator flux and torque comparators. The switching table is also replaced by an SVM Technique, as shown in Figure 2.

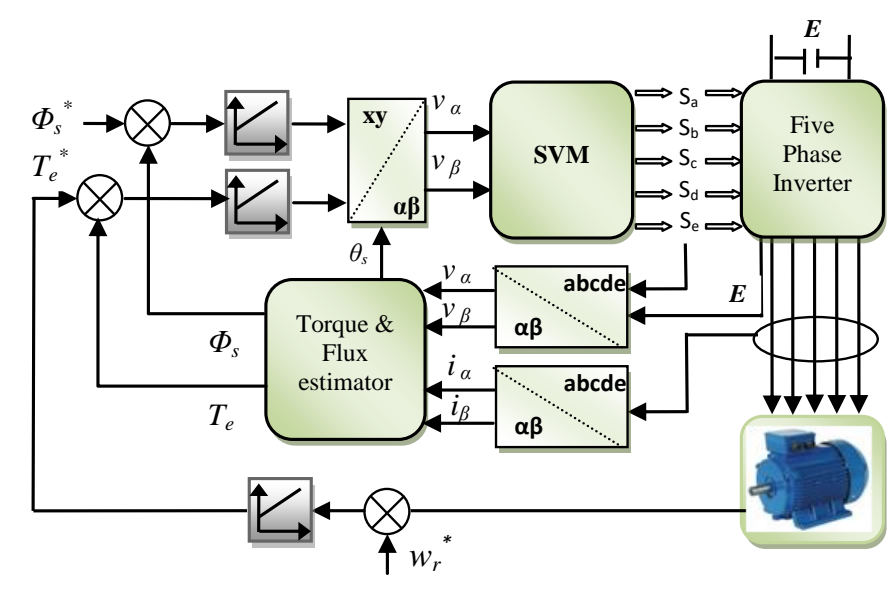

Figure 2. Diagram of DTC-SVM control applied for fivephase IPMSM

\section{FUZZY LOGIC DTC-SVM FOR FIVE-PHASE IPMSM}

Figure 5 represents the technique of the direct torque fuzzy controller (DTFC). The traditional PI controllers for torque and flux have been replaced by two FLC. The $T_{e}{ }^{*}$ and $\Phi_{s}{ }^{*}$ are compared with the values obtained in the $T_{e}$ and $\Phi_{s}$ estimator. The errors are sent to the DTFC control system. The membership function (MF) of the combined input and output variables is generally determined by a common universe of discourse. The FLC is based on the following elements: a fuzzification interface, an inference mechanism, a bases rule and a defuzzification interface $[29,30]$.

The if-then rules to FLC for speed control will be 25 rules. Figure 3 (a), (b) and (c) shows MFs of input variables $E_{w}, d E_{w}$ and output variable respectively (traditional triangular shapes). The MFs is divided into 5 fuzzy. Table 2 shows the 25 fuzzy control rules.

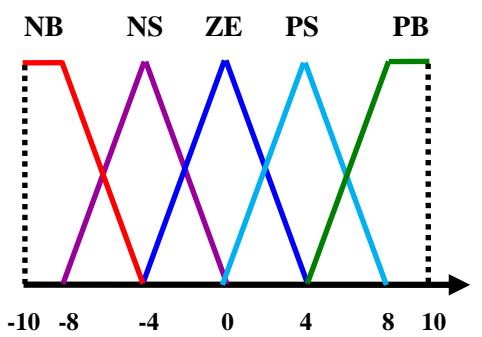

(a)

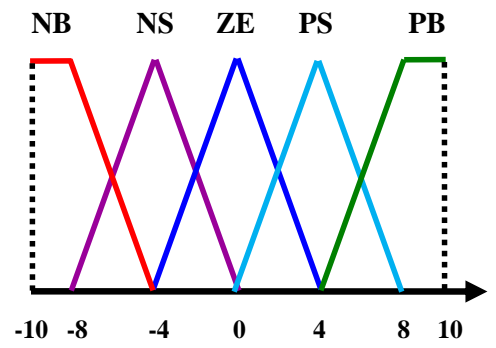

(b) 


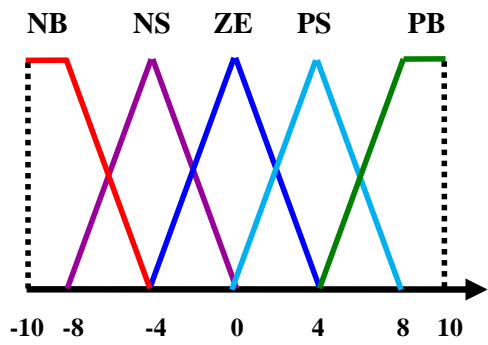

(c)

Figure 3. Speed regulator variables membership: (a) $\boldsymbol{E}_{\boldsymbol{w}}$, (b) $\boldsymbol{d} \boldsymbol{E}_{w},(\mathrm{c})$ output

Table 2. FLC rule base for speed control

\begin{tabular}{ccccccc}
\hline & & \multicolumn{5}{c}{$\boldsymbol{E}_{\boldsymbol{w}}$} \\
\cline { 2 - 7 } & & NS & PB & ZE & NB & PS \\
& NB & ZE & PB & PB & ZE & PB \\
& PB & NB & ZE & NB & NB & ZE \\
& ZE & ZE & NS & ZE & PS & ZE \\
& PS & NS & ZE & NS & NS & ZE \\
& NS & ZE & PS & PS & ZE & PS \\
\hline
\end{tabular}

The fuzzy labels used in this method are positive small (PS), equal zero (ZE), positive big (PB), negative big (NB) and negative small (NS).

The same steps used for the conception of the speed controller (FLC) will be repeated for the torque and flux controller as shown in Figure 4, only we have: $E_{\Phi}=\Phi_{s}{ }^{*}-\Phi_{s}$ for the first fuzzy controller of flux $\Phi_{s}$ and for the second fuzzy controller of torque $E_{T}=T_{e}{ }^{*}-T_{e}$ for the first fuzzy controller of torque $T_{e}$.

We represent the input/output variables by MF, as show in Figure 4, each one divided into 3 fuzzy. Table 3 shows the 9 fuzzy control rules and bestow the change of the FLC output in terms of two inputs $E_{\Phi, T}$ and $d E_{\Phi, T}$.

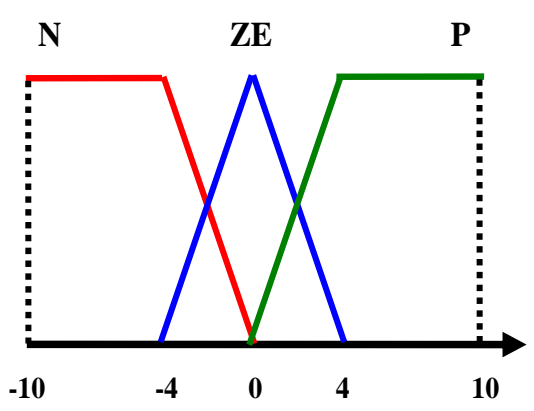

(a)

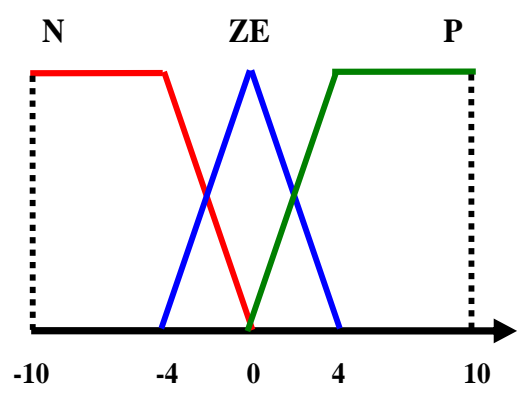

(b)

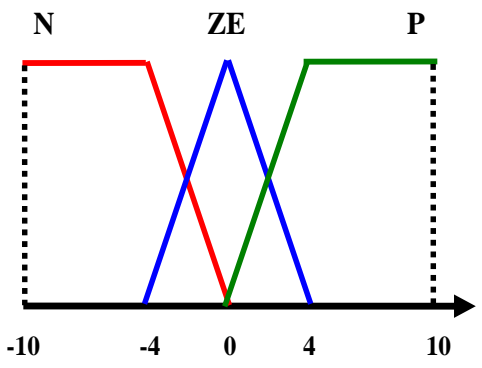

(c)

Figure 4. Torque and flux regulator variables membership: (a) $\boldsymbol{E}_{\Phi, T}$, (b) $\boldsymbol{d} \boldsymbol{E}_{\Phi, T}$, (c) output

Table 3. The rule base for controlling the torque and flux

\begin{tabular}{ccccc}
\hline & & \multicolumn{3}{c}{$\boldsymbol{E}_{\boldsymbol{\Phi}, \boldsymbol{T}}$} \\
\cline { 3 - 5 } & & $\mathrm{P}$ & $\mathrm{Z}$ & $\mathrm{N}$ \\
\multirow{4}{*}{$\boldsymbol{E}_{\boldsymbol{\Phi}, \boldsymbol{T}}$} & $\mathrm{N}$ & $\mathrm{Z}$ & $\mathrm{N}$ & $\mathrm{N}$ \\
& $\mathrm{P}$ & $\mathrm{P}$ & $\mathrm{P}$ & $\mathrm{Z}$ \\
& $\mathrm{Z}$ & $\mathrm{P}$ & $\mathrm{Z}$ & $\mathrm{N}$ \\
\hline
\end{tabular}

The MFs is also assigned with three fuzzy sets: $Z$ (zero), $N$ (negative), $P$ (positive).

The bloc diagram of the DTC-SVM fuzzy for five-phase IPMSM is given by Figure 5.

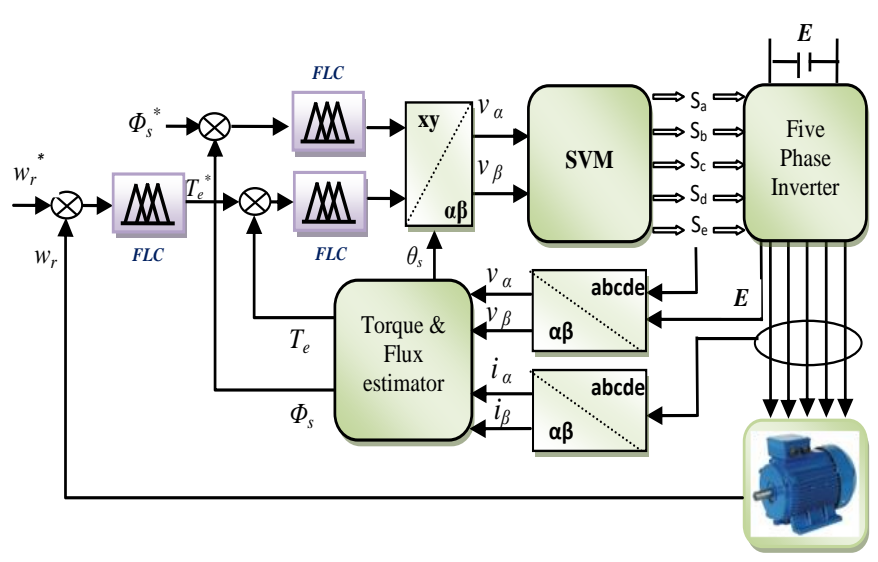

Figure 5. Block diagram of the five-phase IPMSM with DTC-SVM-Fuzzy

\section{SIMULATION RESULTS AND DISCUSSION}

To verify the method proposed in this work, Matlab/Simulink software based simulations were performed. The parameters of the 5-phase IPMSM are as follows: $R_{S}=0.7$

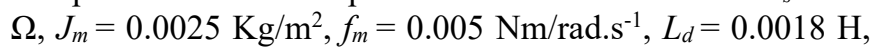
$L_{q}=0.0042 \mathrm{H}, P=2, \phi_{f}=0.5$ web.

Three control strategies: DTC-ST, DTC-SVM and DTCSVM-fuzzy are simulated and compared to reference tracking, sensitivity to load torque change, torque and stator flux ripples, and robustness against variations in machine parameters.

\subsection{Reference tracking test}

Figure 6 show the performance of the 5-phase IPMSM under change in the $T_{r}$ from $0 \mathrm{Nm}$ to $10 \mathrm{Nm}$ at $t=0.3 \mathrm{~s}$, after that, the $T_{r}$ is reduced to $0 \mathrm{Nm}$ at $t=0.6 \mathrm{~s}$. The reference speed is set at 100 to $-100 \mathrm{rad} / \mathrm{s}$ at $t=0.9 \mathrm{~s}$. This figure shows that the 
effect of the $T_{r}$ is very evident on the speed curve of the DTC with the PI controller, while the effects are negligible for the DTC with FLC (see Figure 10). We can see that the latter has an almost ideal speed disturbance rejection (about $2 \%$ ).

Figure 7 presents the response of torque with $T_{r}$ application. A comparison of the results obtained indicates that the DTCSVM- Fuzzy method reduced torque ripple by $68 \%$ compared to traditional DTC and by $20 \%$ compared to DTC-SVM (see Figure 11). These results confirm that the torque ripple in the proposed method has considerably decreased. A comparative study is provided in Table 4.

Figure 8 presents the response of the stator flux for these three methods. It is obvious that DTC-SVM-Fuzzy method can improve steady and dynamic performances of the system and decrease flux ripple (see Figure 12). Figure 9 (a) presents the stator flux loci for traditional DTC. The stator flux locus with the DTC-SVM diagram is shown in Figure 9 (b) and with the DTC-SVM-Fuzzy diagram is shown in Figure 9 (c). In Figure 9 (c) the Lucas of stator flux is improved with very low ripple as compared with classical DTC.

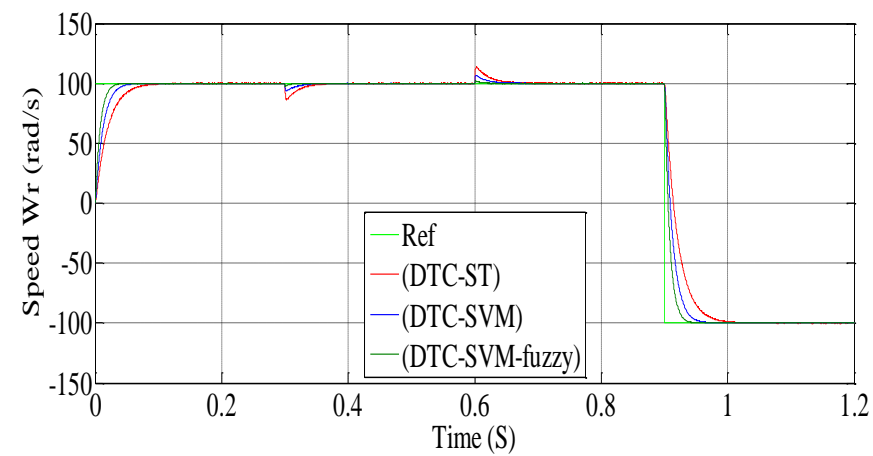

Figure 6. Rotor speed response of the five-phase IPMSM controlled by classical DTC, DTC-SVM and DTC-SVMfuzzy

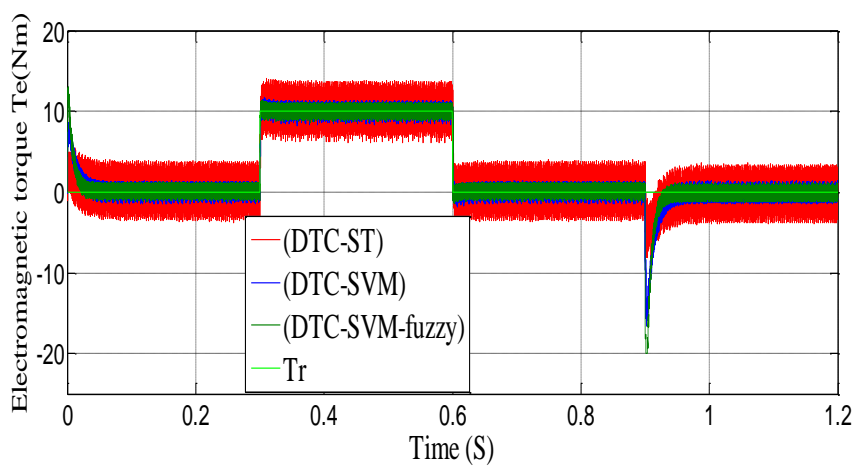

Figure 7. Torque response

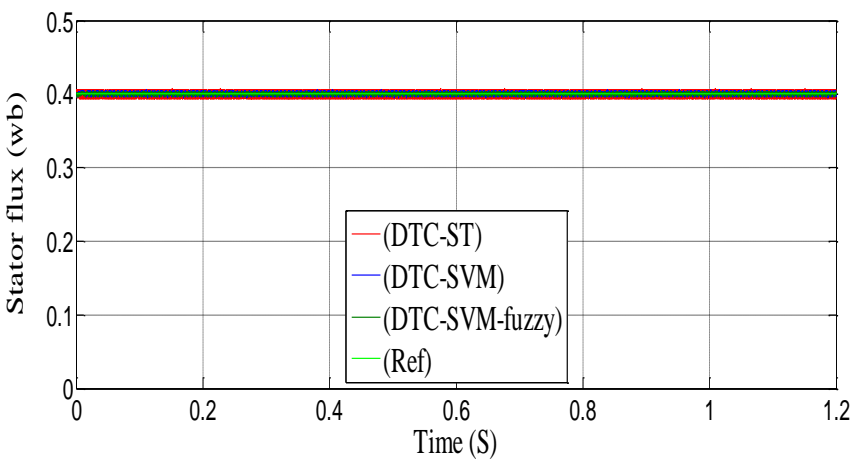

Figure 8. Stator flux response

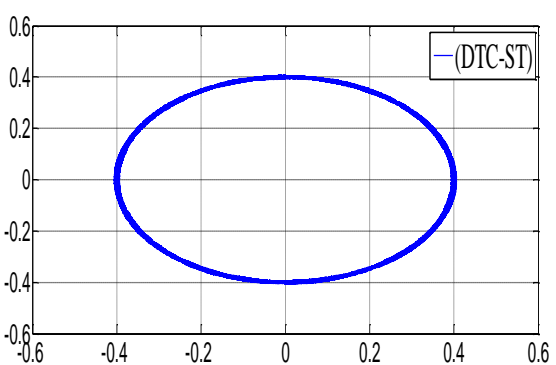

(a)

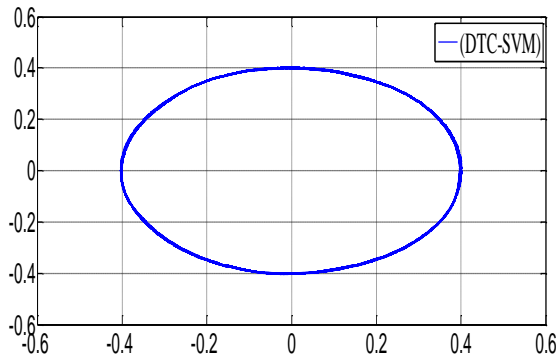

(b)

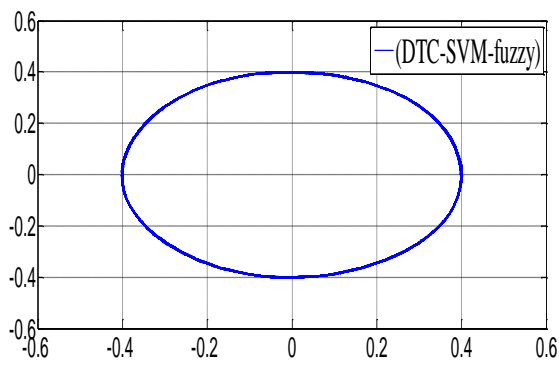

(c)

Figure 9. Stator flux circular trajectory in $\alpha-\beta$ axis: (a) Classical DTC, (b) DTC-SVM, (c) DTC-SVM-fuzzy

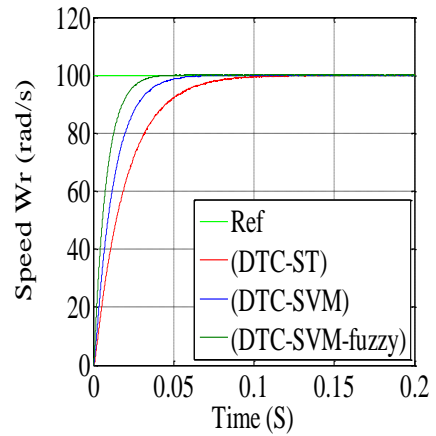

(a)

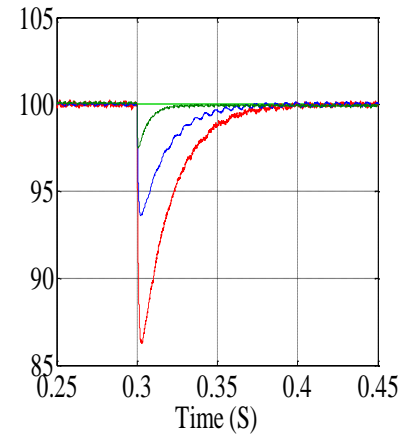

(b)
Figure 10. Zoom in the rotor speed response: (a) When startup, (b) When applying the load torque

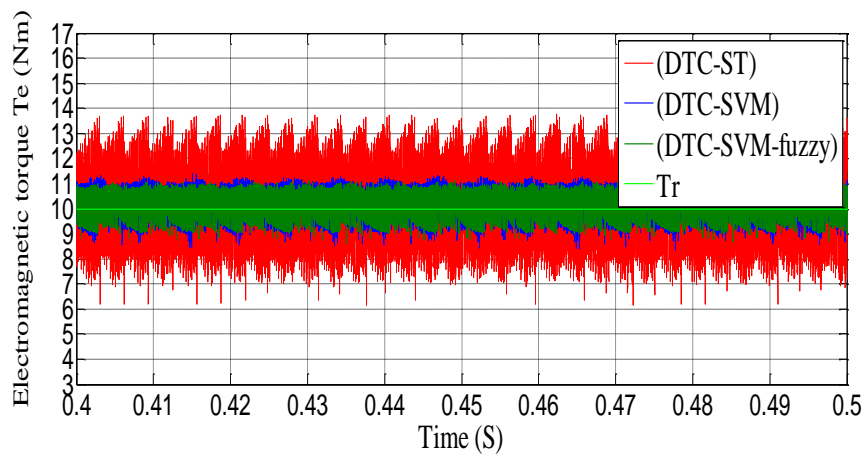

Figure 11. Torque response (Zoom) 


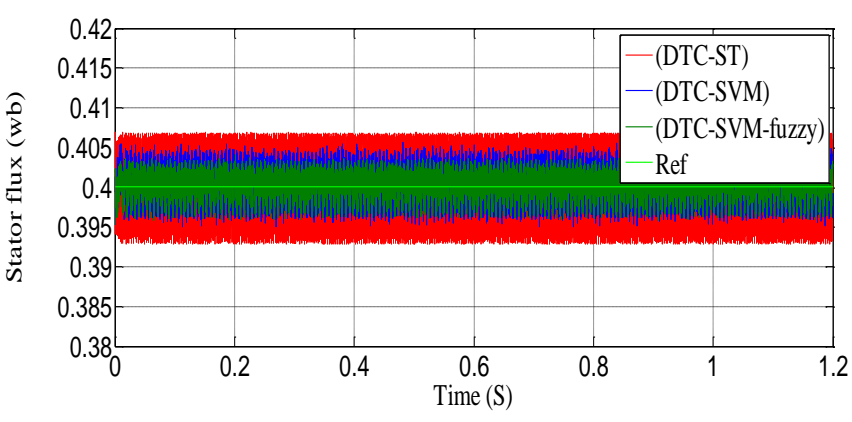

Figure 12. Stator flux (Zoom)

Table 4. Amplitude of ripples

\begin{tabular}{cccc}
\hline & $\begin{array}{c}\text { Traditional } \\
\text { DTC }\end{array}$ & DTC-SVM & $\begin{array}{c}\text { DTC-SVM- } \\
\text { fuzzy }\end{array}$ \\
\hline$T_{e}$ ripples & $6,2-13,6$ & $8,5-11,4$ & $8,9-11,1$ \\
$(\mathrm{Nm})$ & $(\mathbf{7 , 4} \mathrm{Nm})$ & $(\mathbf{2 , 9} \mathrm{Nm})$ & $(\mathbf{2 , 2} \mathrm{Nm})$ \\
$\Phi_{s}$ ripples & $0,393-0,407$ & $0,396-0,405$ & $0,398-0,403$ \\
$(\mathrm{~Wb})$ & $(\mathbf{0 , 0 1 4} \mathrm{Wb})$ & $(\mathbf{0 , 0 0 9} \mathrm{Wb})$ & $\mathbf{( \mathbf { 0 , 0 0 5 } \mathrm { Wb } )}$ \\
\hline
\end{tabular}

\subsection{Robustness test}

To study the robustness of the proposed method, the nominal value of the stator resistance $R_{S}$ and the inertia variation $J_{m}$ is increased by $100 \%, L_{d}$ and $L_{q}$ we reduce them by $50 \%$. Simulation results are shown in Figures 13-18. These variations have a clear effect on the rotor speed, torque and stator flux curves and the effect seems more important to DTC-ST and DTC-SVM control scheme compared to DTCSVM-fuzzy (see Figures 16-18). A comparative study is provided in Table 5. We conclude the FLC that they are more robust to this parameter variation than a PI controller.

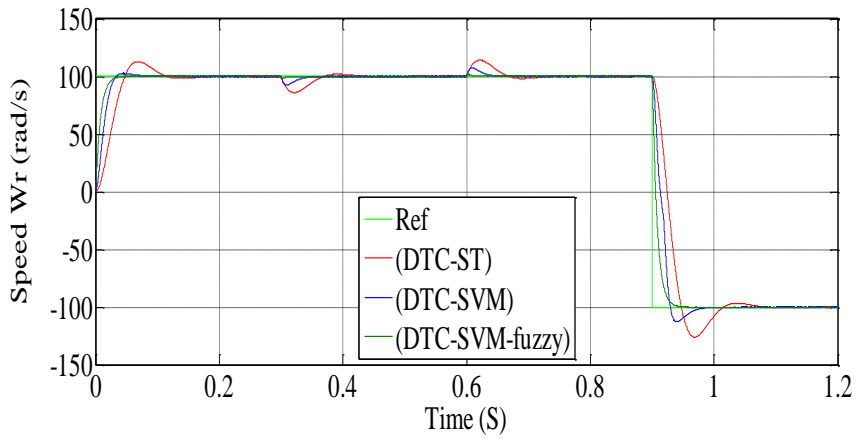

Figure 13. Rotor speed response of the five-phase IPMSM controlled by classical DTC, DTC-SVM and DTC-SVMfuzzy

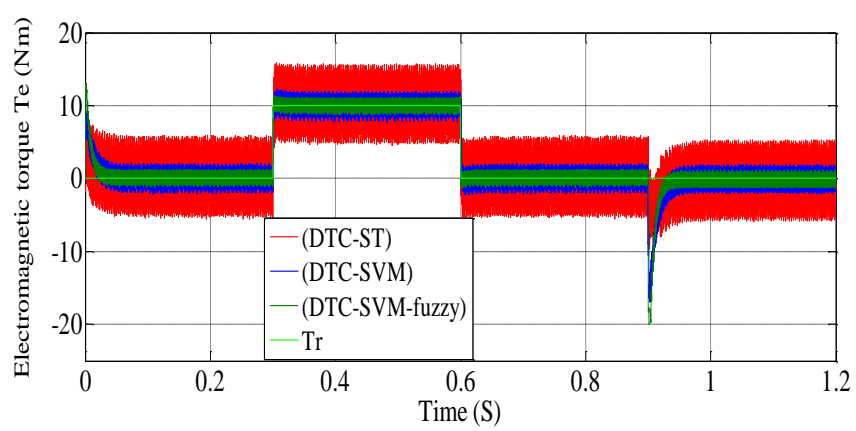

Figure 14. Torque response

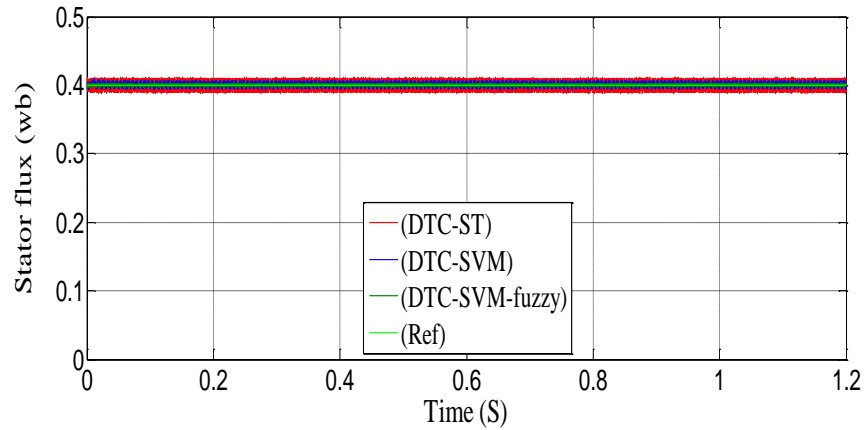

Figure 15. Stator flux response

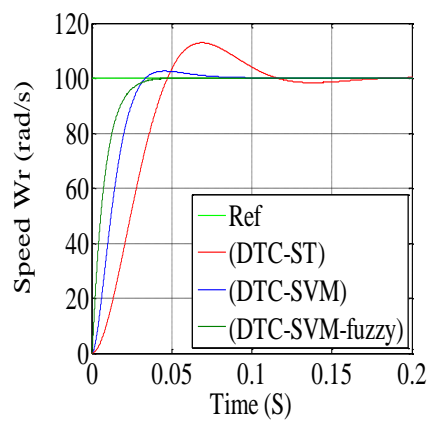

(a)

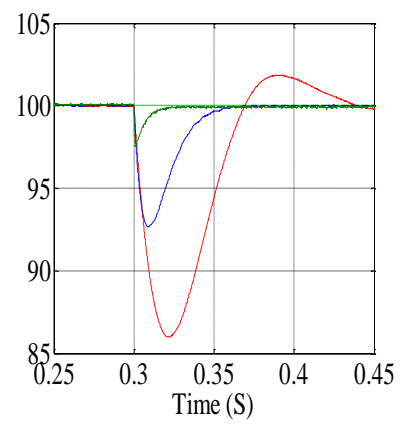

(b)
Figure 16. Zoom in the rotor speed response: (a) When startup, (b) When applying the load torque

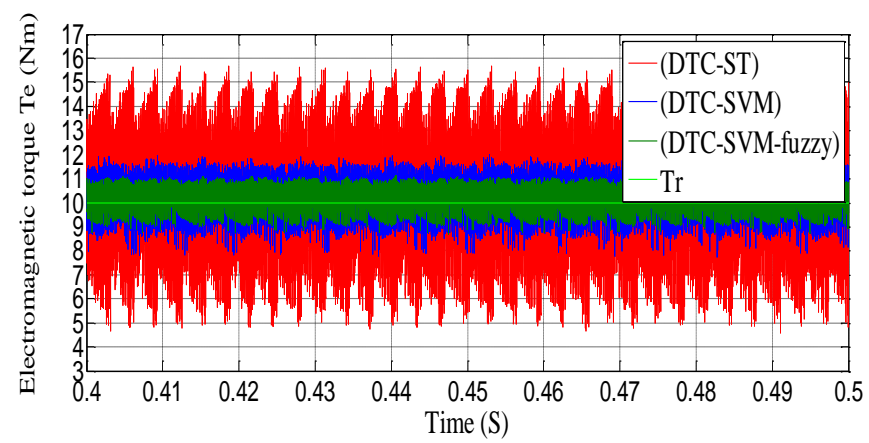

Figure 17. Torque response (Zoom)

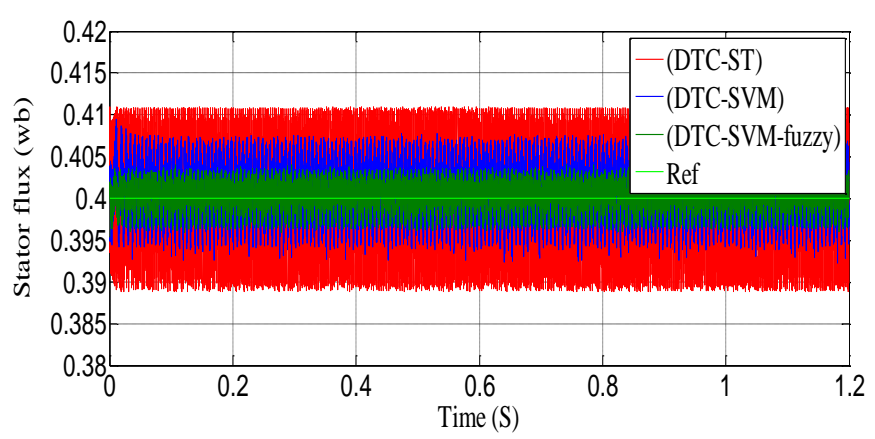

Figure 18. Stator flux (Zoom)

Table 5. Amplitude of ripples

\begin{tabular}{cccc}
\hline & $\begin{array}{c}\text { Traditional } \\
\text { DTC }\end{array}$ & DTC-SVM & $\begin{array}{c}\text { DTC-SVM- } \\
\text { fuzzy }\end{array}$ \\
\hline$T_{e}$ ripples & $4,3-16$ & $7,9-11,9$ & $8,8-11,2$ \\
$(\mathrm{Nm})$ & $(\mathbf{1 1 , 7} \mathrm{Nm})$ & $(\mathbf{4} \mathrm{Nm})$ & $(\mathbf{2 , 4} \mathrm{Nm})$ \\
$\Phi_{s}$ ripples & $0,389-0,411$ & $0,392-0,407$ & $0,397-0,404$ \\
$(\mathrm{~Wb})$ & $(\mathbf{0 , 0 2 2} \mathrm{Wb})$ & $(\mathbf{0 , 0 1 5} \mathrm{Wb})$ & $\mathbf{( 0 , 0 0 7} \mathrm{Wb})$ \\
\hline
\end{tabular}




\section{CONCLUSION}

In this work, a DTFC of the 5P-IPMSM based on SVM was proposed to improve the performance of the DTC technique. Simulation results achieved by the proposed method of DTCSVM with FLC confirm a considerable reduction in ripples of the stator flux, torque ripples and the robustness to the system compared to a traditional DTC system and DTC-SVM with PI controller.

For future works, it will address the experimental validation of the proposed method. Next, it is interesting to extend the DTC-SVM with type-2 fuzzy algorithm add an observer for speed estimation.

\section{REFERENCES}

[1] Catuogno, G.R., Garcia, G.O., Leidhold, R., Guazzi, G. (2016). Fault tolerant control in six-phase PMSM under four open-circuits fault conditions. IEEE International Conference on Industrial Electronics, Ischia, Italy. http://dx.doi.org/10.1109/IECON.2016.7793390

[2] Rangari, S.C., Suryawanshi, H.M, Renge, M. (2018). New fault-tolerant control strategy of five-phase induction motor with four-phase and three-phase modes of operation. Electronics, 7(9): 159-174. http://dx.doi.org/10.3390/electronics7090159

[3] Hosseyni, A., Trabelsi, R., Mimouni, M.F., Iqbal, A. (2018). Fault tolerant vector controlled five-phase permanent magnet synchronous motor drive with an open phase. IEEE International Multi-Conference on Systems, Signals \& Devices (SSD), Hammamet, Tunisia. http://dx.doi.org/10.1109/SSD.2018.8570487

[4] Salehifar, M., Arashloo, R.S., Eguilaz, M.M., Sala, V., Romeral, L. (2015). Observer-based open transistor fault diagnosis and fault-tolerant control of five-phase permanent magnet motor drive for application in electric vehicles. IEEE IET Power Electronics, 8(1): 76-87. http://dx.doi.org/10.1049/iet-pel.2013.0949

[5] Bounadja, E., Boudjema, Z., Djahbar, A. (2019). A new DPC-SVM for matrix converter used in wind energy conversion system based on multiphase permanent magnet synchronous generator. Iranian Journal of Electrical and Electronic Engineering (IJEEE), 15(3): 352-363. https://doi.org/10.22068/IJEEE.15.3.352

[6] Takahashi, I., Noguchi, T. (1986). A new quick-response and high-efficiency control strategy of an induction motor. IEEE Transaction Industry Applications, IA-22 (1):

820-827.

http://dx.doi.org/10.1109/TIA.1986.4504799

[7] Alsofyani, I.M., Idris, N.R.N. (2016). Look-up tablebased DTC of induction machines with improved flux regulation and extended kalman filter state estimator at low speed operation. IEEE Transactions on Industrial Informatics, $12(4)$ :

$1421-1425$ https://doi.org/10.1109/TII.2016.2571682

[8] Ammar, A., Bourek, A. (2017). Nonlinear SVM-DTC for induction motor drive using input-output feedback linearization and high order sliding mode control. ISA Trans, 67(1): 428-442. http://dx.doi.org/10.1016/j.isatra.2017.01.010

[9] Abdul Kadir, M.N.S., Mekhilef, S., Ping, H.W. (2007). Direct torque control permanent magnet synchronous motor drive with asymmetrical multilevel inverter supply.
IEEE 7th International Conference on Power Electronics, Daegu, South Korea. http://dx.doi.org/10.1109/ICPE.2007.4692567

[10] Aghasi, S., Khaburi, D.A., Faraji, V., Behnia, H. (2012). A comparative study on predictive and ISVM direct torque control methods for a doubly fed induction machine fed by an indirect matrix converter. Iranian Journal of Electrical \& Electronic Engineering (IJEEE), 8(2): 138-145.

[11] Benbouhenni, H., Taleb, R. (2017). Commande directe du couple neuronale à 6 secteurs de la machine asynchrone alimentée par onduleur NPC à sept niveaux. Revue Proceedings of Engineering and Technology (PET), 14: 137-142.

[12] Benbouhenni, H., Taleb, R., Chabni, F. (2017). Etude comparative entre la commande DTC trois niveaux et la commande DTC cinq niveaux de la machine asynchrone. Revue Proceedings of Engineering and Technology (PET), 14: 143-149.

[13] Raj, M.S., Saravanan, T., Srinivasan, Y., Srinivasan, Y. (2014). A modified direct torque control of induction motor using space vector modulation technique. MiddleEast Journal of Scientific Research, 20(11): 1572-1574. https://doi.org/10.5829/idosi.mejsr.2014.20.11.114174

[14] Boudjema, Z., Taleb, R., Djerriri, V. Yahdou, A. (2017). A novel direct torque control using second order continuous sliding mode of a doubly fed induction generator for a wind energy conversion system. Turkish Journal of Electrical Engineering \& Computer Sciences, 25(11): 965-975. http://dx.doi.org/10.3906/elk-1510-89

[15] Gao, S.W., Wang, Y.H., Cai, Y., Zhang, C. (2010). Research on reducing torque ripple of DTC fuzzy logicbased. 2nd International Conference on Advanced Computer Control, Shenyang, China. http://dx.doi.org/10.1109/ICACC.2010.5486721

[16] Benbouhenni, H. (2019). Four-level direct torque control of permanent magnet synchronous motor based on neural networks with regulation speed using neural PI controller. Majlesi Journal of Mechatronic Systems, 8(4): 965-975.

[17] Benbouhenni, H. (2018). Seven-level direct torque control of induction motor based on artificial neural networks with regulation speed using fuzzy PI controller. Iranian Journal of Electrical and Electronic Engineering, 14(1): 85-94. http://dx.doi.org/10.22068/IJEEE.14.1.85

[18] Shishehgar, J., Soltani, J., Tabrizchi, A.M., Abjadi, N.R. (2014). Direct torque and flux control of speed sensorless five-phase interior permanent magnet motor based on adaptive sliding mode control. The 5th Annual International Power Electronics, Drive Systems and Technologies Conference (PEDSTC 2014), Tehran. http://dx.doi.org/10.1109/PEDSTC.2014.6799340

[19] Chen, Q., Gu, L., Liu, G. (2019). Extension of spacevector-signal-injection based MTPA control into SVPWM fault-tolerant operation for five-phase IPMSM. IEEE Transactions on Industrial Electronics. http://dx.doi.org/10.1109/TIE.2019.2944066

[20] Tabrizchi, A.M., Soltani, J., Shishehgar, J., Abjadi, N.R. (2019). Direct torque control of speed sensorless fivephase IPMSM based on adaptive input-output feedback linearization. The 5th Annual International Power Electronics, Drive Systems and Technologies Conference (PEDSTC 2014), Tehran. http://dx.doi.org/10.1109/PEDSTC.2014.6799341

[21] Mehedi, F., Nezli, L., Mahmoudi, M.O., Boudjema, Z. 
(2017). Second order sliding mode control of two seriesconnected multi-phase permanent magnet synchronous motor. The Mediterranean Journal of Measurement and Control, 13(3): 795-804.

[22] Mehedi, F., Nezli, L., Mahmoudi, M.O., Belhadj, A (2019). A hybrid of sliding mode control and fuzzy logic control for a five-phase synchronous motor speed control. Springer Nature Switzerland AG 2019, 62: 199-205. http://dx.doi.org/10.1007/978-3-030-04789-4_22

[23] Listwan, J., Pieńkowski, K. (2016). DTC-ST and DTCSVM control of five-phase induction motor with MRASCC estimator. Przegląd Elektrotechniczny, 1(11): 252-256. http://dx.doi.org/10.15199/48.2016.11.61

[24] Tounsi, K., Djahbar, A., Barkat, S. (2016). DTC-SVM of Five-Phase Permanent Magnet Synchronous Motor Drive. IEEE Conf. on Modelling, Identification and Control (ICMIC), Algiers, Algeria http://dx.doi.org/10.1109/ICMIC.2016.7804281

[25] Mehedi, F., Nezli, L., Mahmoudi, M.O. (2018). Speed control of series-connected five-phase two PMSM using sliding mode control. IEEE Conf. on Electrical Sciences and Technologies in Maghreb (CISTEM), Algiers, Algeria. https://doi.org/10.1109/CISTEM.2018.8613341

[26] Zafari, Y., Mazinan, A.H., Majidabad, S.S. (2017). Speed control of five-phase IPMSM through PI, SMC and FITSMC approaches under normal and open phase faulty conditions. Automatika Journal for Control, Measurement, Electronics, Computing and Communications, 58(4): 506-519. http://dx.doi.org/10.1080/00051144.2018.1478928

[27] Mahanta, U., Patnaik, D., Panigrahi, B.P., Panda, A.K. (2015). Dynamic modeling and simulation of SVM-DTC of five phase induction motor. IEEE Conf. on Energy, Power and Environment: Towards Sustainable Growth (ICEPE), Shillong, India. http://dx.doi.org/10.1109/EPETSG.2015.7510062

[28] Zhou, Y., Yan, Z., Duan, Q., Wang, K., Wu, X. (2019). Dynamic direct torque control strategy of five-phase PMSM with load capacity enhancement. IET Power Electronics, 12(3): 598-606. https://doi.org/10.1049/ietpel.2018.5203

[29] Bhukya, J., Mahajan, V. (2018). Fuzzy logic based control scheme for doubly fed induction generator based wind turbine. International Journal of Emerging Electric Power $\quad$ Systems, 19(6): 1-22 http://dx.doi.org/10.1515/ijeeps-2018-0126

[30] Liu, Z., Zheng, Z., Li, Y. (2017). Enhancing faulttolerant ability of a nine-phase induction motor drive system using fuzzy logic current controllers. IEEE Transactions on Energy Conversion, 32(2): 759-769. http://dx.doi.org/10.1109/TEC.2017.2692528

\section{NOMENCLATURE}

$\begin{array}{ll}\text { DTC } & \text { Direct Torque Control } \\ \text { IPMSM } & \begin{array}{l}\text { Interior Permanent Magnet Synchronous } \\ \text { Motor }\end{array} \\ \text { FLC } & \text { Fuzzy Logic Controller }\end{array}$

$\begin{array}{ll}\text { PI } & \text { Proportional-Integral } \\ \text { SVM } & \text { Space Vector Modulation } \\ f_{m} & \text { Viscous damping } \\ J_{m} & \text { Inertia moment } \\ L_{d}, L_{q} & d \text { and } q \text { axis stator inductance } \\ i_{s} & \text { Stator currents } \\ R_{s} & \text { Stator resistance } \\ L_{x}, L_{y} & x \text { and } y \text { axis stator inductance } \\ p & \text { Number of pairs poles } \\ v_{s} & \text { Stator voltages }\end{array}$

\section{Greek symbols}

$\begin{array}{ll}\theta_{r} & \text { Electrical angle } \\ T_{e} & \text { Electromagnetic torque } \\ T_{r} & \text { Load torque } \\ \phi_{f} & \text { Magnetic flux } \\ \theta_{s} & \text { Position of the stator flux } \\ \Phi_{s} & \text { Stator flux }\end{array}$

\section{APPENDIX}

\section{Block diagram of the FLC}

The block diagram of FL controller is shown in Figure 19.

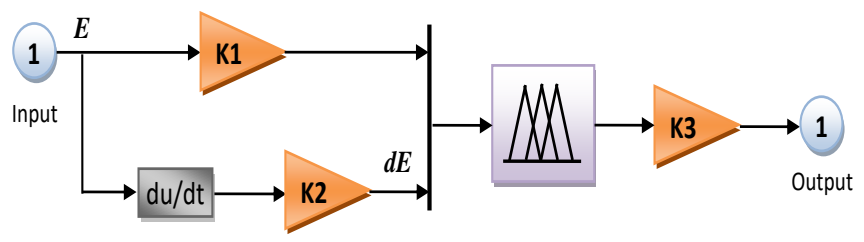

Figure 19. Block diagram of the FL controller

\section{The coefficients of the FLC stator flux, torque and speed controllers}

Table 6 shows the constants values of the stator flux, torque and speed FL controller algorithm gains.

Table 6. FL controller gains

\begin{tabular}{ccccccccc}
\hline \multicolumn{3}{c}{ Stator flux } & \multicolumn{3}{c}{ Torque } & \multicolumn{3}{c}{ Speed } \\
\hline $\mathrm{K} 1$ & $\mathrm{~K} 2$ & $\mathrm{~K} 3$ & $\mathrm{~K} 1$ & $\mathrm{~K} 2$ & $\mathrm{~K} 3$ & $\mathrm{~K} 1$ & $\mathrm{~K} 2$ & $\mathrm{~K} 3$ \\
200 & 0.01 & 50 & 150 & 0.01 & 70 & 70 & 0.4 & 170 \\
\hline
\end{tabular}

The Table 7 shows the parameters of fuzzy controller.

Table 7. Parameters of fuzzy controller

\begin{tabular}{cc}
\hline Fis type & Mamdani \\
\hline And method & Min \\
Or method & Max \\
Implication & Min \\
Aggregation & Max \\
Defuzzification & Centroid \\
\hline
\end{tabular}

